\title{
Human Rhinovirus/Enterovirus in Pediatric Acute Respiratory Distress Syndrome
}

\author{
Michele E. Smith ${ }^{1}$ Patrick T. Wilson ${ }^{1}{ }^{10}$ \\ ${ }^{1}$ Department of Pediatrics, Columbia University Medical Center, \\ New York-Presbyterian Children's Hospital, New York, United States \\ J Pediatr Intensive Care 2020;9:81-86.
}

\begin{abstract}
Address for correspondence Michele E. Smith, MD, Department of Pediatrics, Columbia University Medical Center, New YorkPresbyterian Children's Hospital, 3959 Broadway CHN 10-25, New York, NY 10032, United States (e-mail: mes9138@nyp.org).
\end{abstract}

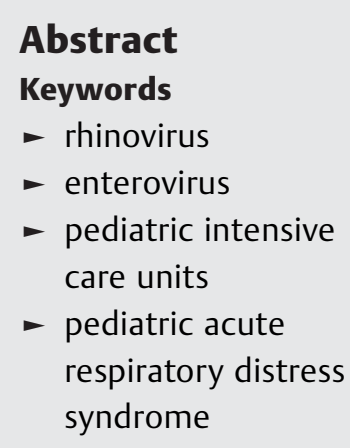

The role of human rhinovirus/enterovirus (HRV/HEV) in severe lower respiratory tract infections remains unclear. We characterized the respiratory status of children admitted to a large academic pediatric intensive care unit (PICU) who tested positive for only $\mathrm{HRV} / \mathrm{HEV}$. One hundred and fifty-five children met inclusion criteria with $62 \%$ requiring positive pressure respiratory support of $5 \mathrm{~cm}$ of water pressure or more within the first 24 hours of admission. Among them, 34\% had $\mathrm{SaO}_{2}$ to $\mathrm{FiO}_{2}$ ratios of 264 or less with 22 patients (14\%) meeting criteria for pediatric acute respiratory distress syndrome. $\mathrm{HRV} / \mathrm{HEV}$ is associated with significant respiratory disease in children admitted to the PICU.

\section{Introduction}

In the 1950s, human rhinovirus (HRV), a member of the Enterovirus genus (HEV) and Picornaviridae family, was first identified as the most important cause of the "common cold." Initial research suggested that HRV is a benign virus restricted to grow within the upper airways of humans. ${ }^{1-3}$ However, current scientific evidence contradicts these early notions and instead suggests that HRV may not be as benign as originally postulated. Recent studies have shown that HRV is not only able to effectively reach, penetrate, and replicate within the lower airway epithelium of individuals in vivo, but that infection with HRV is also associated with histologic changes of the lung interstitium and alveoli. ${ }^{4-6}$ Furthermore, HRV has now been shown to be an important cause of bacterial superinfection, with proposed mechanisms established for infection with Streptococcus pneumoniae and Staphylococcus aureus. ${ }^{7,8}$

Recent clinical studies in pediatrics have also concluded that rhinovirus is associated with lower respiratory tract disease processes. Several studies have demonstrated associations between positivity for HRV and hospital admissions for asthma, bronchiolitis, and pneumonia. ${ }^{9-13}$ Despite the mounting scientific and clinical evidence, it remains controversial as to whether HRV can cause significant respiratory disease as a sole pathogen. This controversy stems from both the long-standing belief that HRV is a benign upper airway pathogen and from studies showing asymptomatic individuals test positive for HRV 12 to $40 \%$ of the time. ${ }^{14-16}$ Additionally, it has also been shown that both HRV and HEV shed in the nasopharynx of children following acute infection for up to 6 weeks and 3 weeks, respectively. ${ }^{17}$ Therefore, it is difficult to show a causal relationship between a positive nasopharyngeal swab for HRV and significant clinical illness.

We aim to characterize children admitted to the pediatric intensive care unit (PICU) at a tertiary children's hospital over a 1-year period who tested positive for HRV/HEV (the hospital clinical assay does not differentiate between the two picornaviruses) with negative blood, urine, respiratory, and cerebrospinal fluid (CSF) bacterial cultures. The goal is to determine if $\mathrm{HRV} / \mathrm{HEV}$ as a sole pathogen is associated with significant lower respiratory tract disease in critically-ill children.

\section{Methods}

\section{Study Design and Patients}

A retrospective study was conducted at a tertiary children's hospital with a 41-bed PICU consisting of a medical-surgical unit, cardiac unit, and neurology unit with approximately 1,800 admissions per year. Children admitted to the PICU between January 1, 2017 and December 31, 2017 with a received

September 16, 2019

accepted after revision

October 12, 2019

published online

November 21, 2019
Copyright $\odot 2020$ by Georg Thieme

Verlag KG, Stuttgart · New York
DOI https://doi.org/ 10.1055/s-0039-3400466. ISSN 2146-4618. 
respiratory pathogen panel (RPP) positive for HRV/HEV were identified. Inclusion criteria included a positive RPP within 1 calendar day of PICU admission, RPP negative for all other viruses and bacteria, and negative blood, urine, respiratory, and cerebrospinal fluid bacterial cultures, if performed. Bacterial cultures were collected within 24 hours before or after PICU admission and the final result was determined after 5 days of incubation. Patients were excluded if admitted postoperatively or did not have a positive RPP within 24 hours of PICU admission.

Approval for the study was obtained by the Institutional Review Board of Columbia University Medical Center.

\section{Detection of HRV/HEV}

Detection of HRV/HEV was performed in the hospital's clinical laboratory using the Biofire FilmArray (Salt Lake City, Utah, United States) nested PCR analysis of submitted nasopharyngeal swabs. The assay detects the following viruses and bacteria at a sensitivity and specificity of 95 and 99\%, respectively: adenovirus, coronavirus OC43, coronavirus NL63, metapneumovirus, $\mathrm{HRV} / \mathrm{HEV}$, influenza $\mathrm{A}$, influenza $\mathrm{A} / \mathrm{H} 1$, influenza $A / H 1-2009$, influenza $A / H 3$, influenza $B$, parainfluenza 1 , parainfluenza 2, parainfluenza 3 , parainfluenza 4 , respiratory syncytial virus, Bordetella pertussis, Chlamydia pneumonia, and Mycoplasma pneumonia. ${ }^{18}$

\section{Data Collection}

Admission vital signs were collected from the electronic medical record (EMR) along with white blood cell count (WBC), C-reactive protein (CRP), admission diagnosis, comorbidities, and outcome data. Fraction of inspired oxygen $\left(\mathrm{FiO}_{2}\right)$ and level of respiratory support at time of admission were recorded and the ratio of oxygen saturation to $\mathrm{FiO}_{2}$ (S:F ratio) was calculated in patients receiving a positive end expiratory pressure (PEEP) of $5 \mathrm{~cm}$ of water pressure or greater. S:F ratios were calculated in patients receiving invasive and noninvasive ventilation as arterial lines were not placed on a majority of patients, thus preventing us from reporting $\mathrm{PaO}_{2}$ to $\mathrm{FiO}_{2}$ ratios in most patients. Chest radiograph (CXR) results as reported by attending radiologists were grouped into the following categories: (1) focal opacity/consolidation/infiltrate, (2) bilateral airspace opacities, (3) other infiltrate (definitive edema and/or atelectasis), and (4) normal. CXRs in categories 1 and 2 were considered to be consistent with pulmonary parenchymal disease. As per the 2015 guidelines from the Pediatric Acute Lung Injury Consensus Conference Group, ${ }^{19}$ children in the study were said to meet criteria for pediatric acute respiratory distress syndrome (pARDS) at the time of PICU admission if (1) they received invasive or noninvasive positive pressure respiratory support of at least $5 \mathrm{~cm}$ of water pressure or greater with S:F ratios less than or equal to 264 , (2) had a CXR consistent with pulmonary parenchymal disease, and (3) had respiratory failure not fully explained by cardiac failure or fluid overload.

\section{Statistical Analysis}

Data were entered into an electronic database and analysis performed in GraphPad Prism version 6 (GraphPad Software,
La Jolla, California, United States). Median and interquartile range (IQR) or number with corresponding percentage are reported.

\section{Results}

\section{Patients}

A total of 734 patients admitted to the PICU in 2017 were tested positive for HRV/HEV. Among them, 538 were excluded secondary to their RPPs not being collected within one day of PICU admission or the patient being postoperative. Another 17 patients were excluded because the RPP was positive for other viruses and 24 more children were excluded because of a positive bacterial culture. Ultimately, 155 children met the defined inclusion criteria with $\mathrm{HRV} / \mathrm{HEV}$ isolated as a sole pathogen within one calendar day of PICU admission (-Fig. 1).

Patient characteristics, admission vital signs, laboratory data, and outcomes are shown in - Table 1. The median age of the study population was 4 years (IQR $=1-8)$ with a median admission WBC count of $12,000 / \mu \mathrm{L}(\mathrm{IQR}=9-17)$ and CRP of $22 \mathrm{mg} / \mathrm{L}$ (reference range $0-10 \mathrm{mg} / \mathrm{L}$; IQR 3-83). The most common comorbidities of the population were pulmonary (33\%) and cardiac disease (17\%,) while 25 (15\%) of patients had none (-Table 2 ). In terms of seasonality, the majority of patients with HRV/HEV were admitted in March, May, September, and October (-Fig. 2). The most common PICU admission diagnoses were status asthmaticus (55\%), acute respiratory failure (54\%), bronchiolitis (5\%), and shock (5\%). One hundred twenty-five children (81\%) were transferred to the floor after their PICU admission, 28 (18\%) were sent

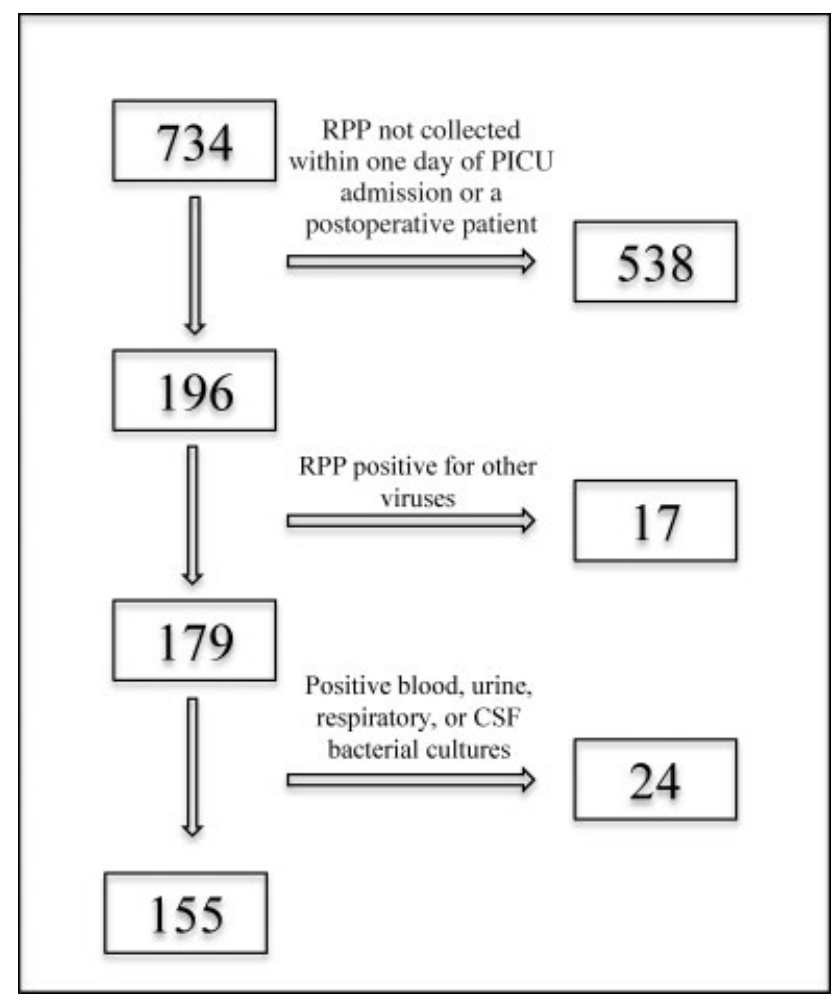

Fig. 1 Enrolment flow chart. CSF, cerebrospinal fluid; PICU, pediatric intensive care unit; RPP, respiratory pathogen panel. 
Table 1 Baseline characteristics and disposition from the PICU

\begin{tabular}{|c|c|}
\hline Patient characteristics & $\begin{array}{l}\text { Median (IQR) } \\
\text { or } n(\%)\end{array}$ \\
\hline Age $(y)$ & $4(1-8)$ \\
\hline Weight $(\mathrm{kg})$ & $17(11-27)$ \\
\hline Sex (female) & $65(42)$ \\
\hline Systolic blood pressure (mm Hg) & $105(97-118)$ \\
\hline Heart rate (beats per min) & $147(127-160)$ \\
\hline Respiratory rate (breaths per min) & $29(24-36)$ \\
\hline Oxygen saturation (\%) & 97 (95-99) \\
\hline Temperature $\left({ }^{\circ} \mathrm{C}\right)$ & $37(36-37)$ \\
\hline $\begin{array}{l}\text { White blood cell count } \\
\text { (number/ } \mu \mathrm{L} ; n=102 \text { ) }\end{array}$ & $12(9-17)$ \\
\hline $\begin{array}{l}\text { C-reactive protein } \\
\text { (reference range } 0-10 \mathrm{mg} / \mathrm{L} ; n=44 \text { ) }\end{array}$ & $22(3-83)$ \\
\hline Transferred to floor & $125(81)$ \\
\hline Discharged home & $28(18)$ \\
\hline Death & $2(1)$ \\
\hline
\end{tabular}

Abbreviations: IQR, interquartile range; PICU, pediatric intensive care unit. Note: number $(n)$, percentage (\%). $n=155$ unless otherwise specified.

Table 2 Comorbidities of the study population

\begin{tabular}{|l|l|}
\hline $\begin{array}{l}\text { Comorbidity } \\
\boldsymbol{n}=\mathbf{1 6 8} \text { comorbidities }\end{array}$ & Number (\%) \\
\hline Pulmonary & $56(33)$ \\
\hline Cardiac & $28(17)$ \\
\hline None & $25(15)$ \\
\hline Genetic & $17(10)$ \\
\hline Neurologic & $14(8)$ \\
\hline Prematurity & $9(5)$ \\
\hline Oncologic & $7(4)$ \\
\hline Endocrine & $5(3)$ \\
\hline Gastrointestinal & $2(1)$ \\
\hline Hematologic & $2(1)$ \\
\hline Renal & $1(0.6)$ \\
\hline ENT & $1(0.6)$ \\
\hline Musculoskeletal & $1(0.6)$ \\
\hline
\end{tabular}

Abbreviation: ENT, ear-nose-tongue.

Note: thirteen of the 155 children had more than one comorbidity making a total of 168 comorbidities.

directly home from the PICU, and 2 children (1\%) died during their PICU stay ( $\mathbf{- T a b l e ~} \mathbf{1}$ ).

\section{Respiratory Support, S:F Ratio, and CXR Data}

Ninety-six children (62\%) admitted to the PICU with HRV/HEV required respiratory pressure support with a PEEP of at least $5 \mathrm{~cm}$ of water pressure. At the time of PICU admission, 53 patients (34\%) required bi-level positive airway pressure (BPAP), 29(19\%) required continuous positive airway pressure
(CPAP), 12 (8\%) required invasive mechanical ventilation via endotracheal tube, and 2 (1\%) were mechanically ventilated via tracheostomy. Of the 97 patients on positive pressure ventilation (including ventilation by endotracheal tube, tracheostomy, BPAP, and CPAP), 34 patients (35\%) had admission $S: F$ ratios $\leq 264$. One hundred and twenty-seven patients had an admission CXR. Fifty-nine CXRs (46\%) demonstrated a focal opacity/infiltrate/consolidation or bilateral airspace opacities consistent with pulmonary parenchymal disease ( $\mathbf{- T a b l e ~} \mathbf{3}$ ). Ultimately, 22 (14\%) patients were on positive pressure respiratory support with S:F ratios $\leq 264$, CXR data consistent with pulmonary parenchymal disease and respiratory disease not consistent with cardiac failure or fluid overload, thus meeting the criteria for pARDS criteria.

\section{Individuals Meeting pARDS Criteria}

Characteristics of the 22 patients meeting pARDS criteria are shown in - Table 4. Fifteen of the 22 patients were diagnosed with acute respiratory failure, 4 with status asthmaticus, and 1 with ARDS, intracranial hemorrhage, and status epilepticus each. A majority of the patients had comorbidities while $14 \%$ of children were previously healthy.

\section{Discussion}

Growing evidence supports the hypothesis that HRV is a pathogen of the lower respiratory tract and can contribute to significant respiratory disease in pediatric patients. To our knowledge, only one previous study has focused specifically on the pediatric critical care population admitted with HRV/HEV. Spaeder et al performed a retrospective cohort study to describe pediatric mortality in the PICU population who tested positive for $\mathrm{HRV} / \mathrm{HEV} .^{20}$ Our study is unique in that it focuses on the PICU population with HRV/HEV isolated as a sole pathogen. Their study used the 1994 AmericanEuropean Consensus Criteria for Acute Respiratory Distress Syndrome for an ARDS diagnosis, whereas the current study uses the 2015 guidelines from the Pediatric Acute Lung Injury Consensus Conference Group. ${ }^{19,21}$ Other studies have described children admitted to the hospital with $\mathrm{HRV} / \mathrm{HEV}$, with a subset of children ultimately requiring admission to the ICU, and/or requiring mechanical ventilation. ${ }^{9,10,22-24}$ Some studies concluded that children admitted with HRV/HEV were as likely to require ICU admission or need mechanical ventilation, as children admitted with other respiratory viruses historically considered to be more severe, such as influenza. ${ }^{22,23}$ Our results in combination with other studies suggest that HRV/HEV is not an innocent by-stander and is associated with significant respiratory disease in pediatric patients.

It is important to note that the majority of children in our cohort had one or more comorbidities, with the most common being underlying cardiopulmonary disease. Previous studies also reported that a majority of children requiring hospitalization for HRV/HEV had underlying chronic medical conditions involving the cardiorespiratory, immune, or neurologic system, as well as prematurity. ${ }^{11-13,25}$ However, Messacar et al found that half of the children in their study 


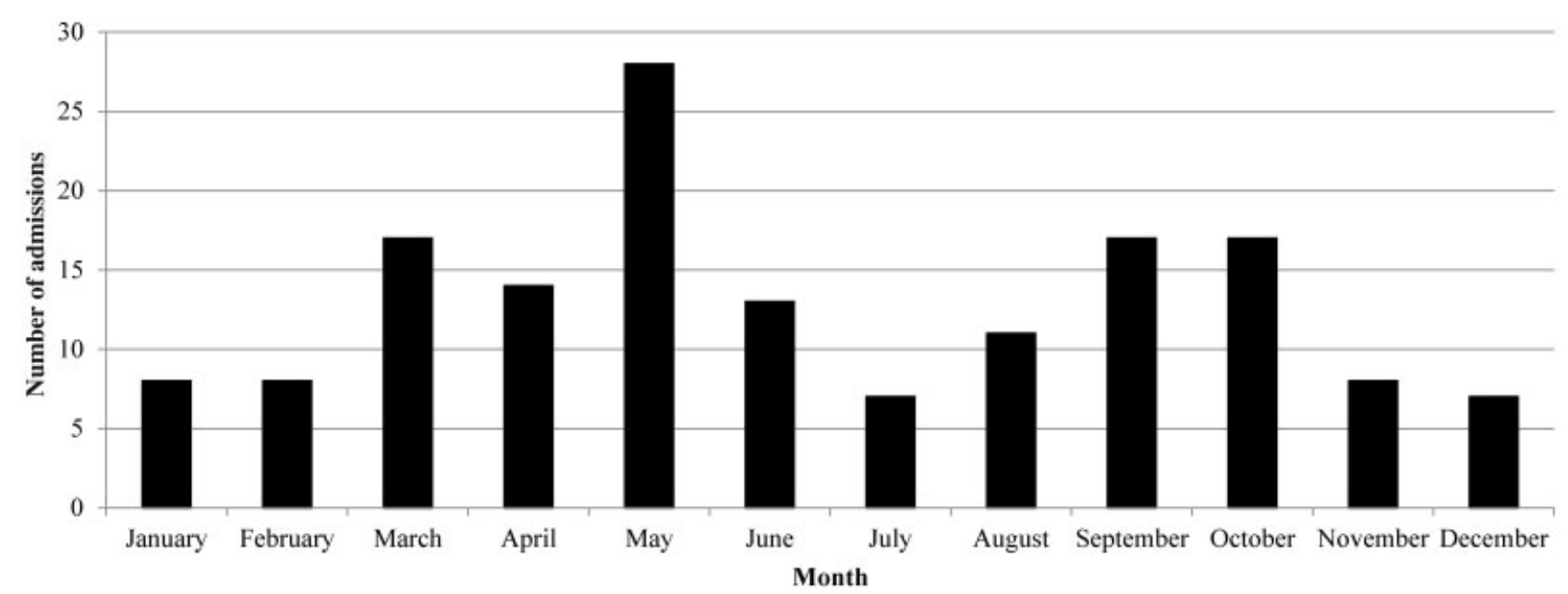

Fig. 2 Number of admissions for children positive for only HRV/HEV by calendar month. HEV, enterovirus; HRV, rhinovirus.

Table 3 Respiratory support, S:F ratios, chest radiograph categories, and pARDS criteria at time of PICU admission

\begin{tabular}{|l|l|}
\hline $\begin{array}{l}\text { Highest level of respiratory support } \\
\text { in first } 24 \mathrm{~h}\end{array}$ & Number (\%) \\
\hline BPAP & $53(34)$ \\
\hline Room air & $40(26)$ \\
\hline CPAP & $29(19)$ \\
\hline Intubated & $12(8)$ \\
\hline Facemask & $11(7)$ \\
\hline Nasal cannula & $4(3)$ \\
\hline Nonrebreather & $3(2)$ \\
\hline High-flow nasal cannula & $1(0.6)$ \\
\hline Tracheostomy to ventilator & $2(1)$ \\
\hline Admission S:F $\leq 264$ ( $n=97)$ & $34(35)$ \\
\hline Chest radiograph category $(n=127):$ & $25(20)$ \\
$\begin{array}{l}\text { 1. Focal opacity/consolidation/infiltrate } \\
\text { 3. Bilateral airspace opacities } \\
\text { 4. Normal }\end{array}$ & $34(27)$ \\
\hline $\begin{array}{l}\text { Pediatric acute respiratory } \\
\text { distress syndrome }\end{array}$ & $35(28)$ \\
\hline Patients meeting criteria & \\
\hline Patients not meeting criteria & $22(14)$ \\
\hline
\end{tabular}

Abbreviations: BPAP, bi-level positive airway pressure; CPAP, continuous positive airway pressure; PARDS, pediatric acute respiratory distress syndrome; PICU, pediatric intensive care unit; S:F, ratio of oxygen saturation to $\mathrm{FiO}_{2}$.

Note: Oxygen saturation to fraction of inspired oxygen ratio (S:F) was calculated for patients receiving invasive or noninvasive positive pressure ventilation of at least $5 \mathrm{~cm} \mathrm{H}_{2} \mathrm{O}$.

requiring hospitalization with $\mathrm{HRV} / \mathrm{HEV}$ were previously healthy. ${ }^{22}$ In our study, 25 children had no comorbidities and still required admission to the PICU. Furthermore, 3 out of 22 children who met criteria for pARDS in our study had no previous medical history, demonstrating that previously healthy children can have significant clinical illness in the setting of HRV/HEV positivity and require admission to the PICU.

PICU admissions for HRV/HEV occurred throughout the year with peak activity in March, May, September, and October. This finding is consistent with previous studies reporting biannual peaks of HRV/HEV infection in Spring and Fall. ${ }^{10,24,26}$ The majority of children in our cohort had an admission diagnosis of status asthmaticus. Johnston et al showed that HRV infection accounted for two-thirds of all virally induced severe asthma exacerbations in the cohort of children studied. ${ }^{27}$ Additionally, Miller et al showed that children with a history of wheezing or asthma had the highest rate of HRV-associated hospital admissions, drawing further associations between HRV and airway reactivity. ${ }^{10}$

Sixty-two percent of patients in the study required positive pressure respiratory support during their ICU admission with $14 \%$ meeting criteria for pARDS. Spaeder et al also examined children admitted to the PICU with HRV/HEV and retrospectively examined how many patients met multiple organ dysfunction syndrome (MODS) and ARDS criteria. ${ }^{21,28}$ The rate of MODS and ARDS in their study was 3 and $2 \%$, respectively. ${ }^{20}$ Three case reports are reporting associations between HRV/HEV and ARDS in individuals under the age of 22 years have also been published. ${ }^{29-31}$ Our study, in combination with previous data, highlights the importance of physicians being aware that children admitted with $\mathrm{HRV} / \mathrm{HEV}$, as the sole pathogen are at risk of developing pARDS.

\section{Limitations}

There are several limitations to this single-center, retrospective study including the lack of a control group including patients with negative RPPs, missing documentation of patient symptomatology, and inability of the RPP to differentiate between the two picornaviruses, HRV and HEV. Additionally, our study was limited to the first day of PICU admission preventing us from following the progression of respiratory disease throughout the hospital stay and potentially missing patients testing positive for HRV/HEV later in their admission. 
Table 4 Characteristics of the 22 patients meeting pediatric acute respiratory distress syndrome criteria

\begin{tabular}{|c|c|c|c|c|c|c|}
\hline $\begin{array}{l}\text { Age } \\
\text { (y) }\end{array}$ & Sex & $\begin{array}{l}\mathrm{S}: \mathrm{F} \\
\text { ratio }\end{array}$ & $\begin{array}{l}\text { Admission } \\
\text { respiratory } \\
\text { support }\end{array}$ & $\begin{array}{l}\text { Chest } \\
\text { radiograph } \\
\text { category }\end{array}$ & Admission diagnosis & Comorbidities \\
\hline 0 & $\mathrm{~F}$ & 194 & Intubated & 2 & Shock & Endocrine \\
\hline 1 & $\mathrm{M}$ & 240 & BPAP & 2 & Status asthmaticus & None \\
\hline 13 & $\mathrm{~F}$ & 198 & BPAP & 2 & Status asthmaticus & Asthma \\
\hline 7 & $\mathrm{M}$ & 200 & Intubated & 2 & Acute respiratory failure & Prematurity, neurologic \\
\hline 1 & $\mathrm{M}$ & 242 & BPAP & 2 & Status asthmaticus & None \\
\hline 11 & $\mathrm{~F}$ & 242 & Tracheostomy to ventilator & 1 & Acute respiratory failure & Musculoskeletal, genetic \\
\hline 1 & $M$ & 232 & BPAP & 2 & Acute respiratory failure & Neurologic \\
\hline 7 & $\mathrm{M}$ & 188 & BPAP & 2 & Acute respiratory failure & Neurologic \\
\hline 8 & M & 217 & CPAP & 1 & Acute respiratory failure & Asthma \\
\hline 1 & $\mathrm{M}$ & 198 & BPAP & 1 & Acute respiratory failure & Prematurity \\
\hline 3 & $\mathrm{M}$ & 98 & Intubated & 1 & Intracranial hemorrhage & Oncologic \\
\hline 0 & $M$ & 245 & BPAP & 2 & Acute respiratory failure & Hematologic \\
\hline 1 & $\mathrm{~F}$ & 222 & Intubated & 2 & Status epilepticus & Neurologic \\
\hline 2 & M & 245 & CPAP & 2 & Acute respiratory failure & Prematurity \\
\hline 15 & M & 69 & BPAP & 2 & Acute respiratory failure & Genetic, cardiac \\
\hline 0 & M & 154 & Intubated & 2 & Acute respiratory failure & None \\
\hline 20 & $\mathrm{M}$ & 222 & BPAP & 2 & Acute respiratory failure & Oncologic \\
\hline 1 & $\mathrm{M}$ & 125 & Intubated & 2 & ARDS & Cardiac \\
\hline 2 & $M$ & 138 & BPAP & 2 & Acute respiratory failure & Genetic \\
\hline 13 & $\mathrm{~F}$ & 208 & BPAP & 2 & Acute respiratory failure & Neurologic, cardiac \\
\hline 7 & M & 132 & CPAP & 1 & Status asthmaticus & Asthma \\
\hline 0 & M & 94 & Intubated & 2 & Acute respiratory failure & Prematurity \\
\hline
\end{tabular}

Abbreviations: BPAP, bi-level positive airway pressure; CPAP, continuous positive airway pressure; $F$, female; $M$, male; $S$ :F, ratio of oxygen saturation to $\mathrm{FiO}_{2}$.

\section{Conclusion}

In conclusion, a majority of children admitted to the PICU with $\mathrm{HRV} / \mathrm{HEV}$, as a sole pathogen required positive pressure ventilation with $14 \%$ meeting criteria for pARDS. Future prospective, controlled studies differentiating HRV from HEV are needed to definitively prove HRV/HEV alone can lead to pARDS and to provide a better understanding of the natural disease course throughout hospital admissions.

Funding

None.

\section{Conflict of Interest}

None declared.

\section{References}

1 Stott EJ, Heath GF. Factors affecting the growth of Rhinovirus 2 in suspension cultures of L132 cells. J Gen Virol 1970;6(01):15-24

2 Tyrrell DA, Parsons R. Some virus isolations from common colds. III. Cytopathic effects in tissue cultures. Lancet 1960;1(7118):239-242

3 Winther B, Brofeldt S, Christensen B, Mygind N. Light and scanning electron microscopy of nasal biopsy material from patients with naturally acquired common colds. Acta Otolaryngol 1984;97 $(3,4): 309-318$

4 Papadopoulos NG, Sanderson G, Hunter J, Johnston SL. Rhinoviruses replicate effectively at lower airway temperatures. J Med Virol 1999;58(01):100-104

5 Papadopoulos NG, Bates PJ, Bardin PG, et al. Rhinoviruses infect the lower airways. J Infect Dis 2000;181(06):1875-1884

6 Gutman JA, Peck AJ, Kuypers J, Boeckh M. Rhinovirus as a cause of fatal lower respiratory tract infection in adult stem cell transplantation patients: a report of two cases. Bone Marrow Transplant 2007;40(08):809-811

7 Ishizuka S, Yamaya M, Suzuki T, et al. Effects of rhinovirus infection on the adherence of Streptococcus pneumoniae to cultured human airway epithelial cells. J Infect Dis 2003;188(12):1928-1939

8 Passariello C, Schippa S, Conti C, et al. Rhinoviruses promote internalisation of Staphylococcus aureus into non-fully permissive cultured pneumocytes. Microbes Infect 2006;8(03):758-766

9 El-Sahly HM, Atmar RL, Glezen WP, Greenberg SB. Spectrum of clinical illness in hospitalized patients with "common cold" virus infections. Clin Infect Dis 2000;31(01):96-100

10 Miller EK, Lu X, Erdman DD, et al; New Vaccine Surveillance Network. Rhinovirus-associated hospitalizations in young children. J Infect Dis 2007;195(06):773-781

11 McMillan JA, Weiner LB, Higgins AM, Macknight K. Rhinovirus infection associated with serious illness among pediatric patients. Pediatr Infect Dis J 1993;12(04):321-325 
12 Krilov L, Pierik L, Keller E, et al. The association of rhinoviruses with lower respiratory tract disease in hospitalized patients. J Med Virol 1986;19(04):345-352

13 Kim JO, Hodinka RL. Serious respiratory illness associated with rhinovirus infection in a pediatric population. Clin Diagn Virol 1998;10(01):57-65

14 Johnston SL, Sanderson G, Pattemore PK, et al. Use of polymerase chain reaction for diagnosis of picornavirus infection in subjects with and without respiratory symptoms. J Clin Microbiol 1993;31 (01):111-117

15 Nokso-Koivisto J, Kinnari TJ, Lindahl P, Hovi T, Pitkäranta A. Human picornavirus and coronavirus RNA in nasopharynx of children without concurrent respiratory symptoms. J Med Virol 2002;66(03):417-420

16 Rakes GP, Arruda E, Ingram JM, et al. Rhinovirus and respiratory syncytial virus in wheezing children requiring emergency care. IgE and eosinophil analyses. Am J Respir Crit Care Med 1999;159 (03):785-790

17 Jartti T, Lehtinen P, Vuorinen T, Koskenvuo M, Ruuskanen O. Persistence of rhinovirus and enterovirus RNA after acute respiratory illness in children. J Med Virol 2004;72(04): 695-699

18 Poritz MA, Blaschke AJ, Byington CL, et al. FilmArray, an automated nested multiplex PCR system for multi-pathogen detection: development and application to respiratory tract infection. PLoS One 2011;6(10):e26047

19 Pediatric Acute Lung Injury Consensus Conference Group. Pediatric acute respiratory distress syndrome: consensus recommendations from the Pediatric Acute Lung Injury Consensus Conference. Pediatr Crit Care Med 2015;16(05):428-439

20 Spaeder MC, Custer JW, Miles AH, et al. A multicenter outcomes analysis of children with severe rhino/enteroviral respiratory infection. Pediatr Crit Care Med 2015;16(02):119-123

21 Bernard GR, Artigas A, Brigham KL, et al. The American-European Consensus Conference on ARDS. Definitions, mechanisms, rele- vant outcomes, and clinical trial coordination. Am J Respir Crit Care Med 1994;149(3, Pt 1):818-824

22 Messacar K, Robinson CC, Bagdure D, Curtis DJ, Glodé MP, Dominguez SR. Rhino/enteroviruses in hospitalized children: a comparison to influenza viruses. J Clin Virol 2013;56(01):41-45

23 Iwane MK, Prill MM, Lu X, et al. Human rhinovirus species associated with hospitalizations for acute respiratory illness in young US children. J Infect Dis 2011;204(11):1702-1710

24 Rudi JM, Molina F, Díaz R, et al. The role of rhinovirus in children hospitalized for acute respiratory disease, Santa Fe, Argentina. J Med Virol 2015;87(12):2027-2032

25 Louie JK, Roy-Burman A, Guardia-Labar L, et al. Rhinovirus associated with severe lower respiratory tract infections in children. Pediatr Infect Dis J 2009;28(04):337-339

26 Lambert SB, Allen KM, Druce JD, et al. Community epidemiology of human metapneumovirus, human coronavirus NL63, and other respiratory viruses in healthy preschool-aged children using parent-collected specimens. Pediatrics 2007;120(04):e929-e937

27 Johnston SL, Pattemore PK, Sanderson G, et al. Community study of role of viral infections in exacerbations of asthma in 9-11 year old children. BMJ 1995;310(6989):1225-1229

28 Goldstein B, Giroir B, Randolph A; International Consensus Conference on Pediatric Sepsis. International pediatric sepsis consensus conference: definitions for sepsis and organ dysfunction in pediatrics. Pediatr Crit Care Med 2005;6(01):2-8

29 Ceylan G, İsgüder R, Ahu Kara A, Gülfidan G, Ağın H, Devrim İ. Acute respiratory distress syndrome caused by rhinovirus. Journal of Pediatric Infection 2017;11:E84-E87

30 Soni P, Rai A, Aggarwal N, Kamholz S, Yoon T, Kupfer Y Enterovirus/human rhinovirus: a rare cause of acute respiratory distress syndrome. Crit Care Med 2016;44:523

31 Dalal P, Varma D. Enterovirus-rhinovirus pneumonia leading to acute respiratory distress syndrome (ARDS) requiring mechanical ventilation in a nonimmunocompromised healthy adult. Chest 2012; $142: 341 \mathrm{~A}$ 